\title{
Epidemiological and Clinical Features of 308 Hospitalized Patients with Novel 2009 Influenza A (H1N1) Virus Infection in China during the First Pandemic Wave
}

\author{
Guoliang Zhanga, ${ }^{a}$ Zhang Xiab Yingxia Liub Xiuhui Lic ${ }^{\mathrm{c}}$ Xinghua Tan ${ }^{\mathrm{d}}$ \\ Yimei Tianc Lianchun Liang ${ }^{c}$ Guang Nie $^{\mathrm{b}}$ Boping Zhou ${ }^{\mathrm{a}, \mathrm{b}}$ \\ a Department of Infectious Diseases, Renmin Hospital of Wuhan University, Wuhan, ${ }^{b}$ Shenzhen Institute of \\ Infectious Diseases, Shenzhen Third Renmin Hospital, Shenzhen, 'Department of Infectious Diseases, \\ Affiliated Beijing Youan Hospital, Capital Medical University, Beijing, and ${ }^{\mathrm{d}}$ Department of Infectious Diseases, \\ Guangzhou Eighth Renmin Hospital, Guangzhou, China
}

\section{Key Words}

H1N1, clinical features $\cdot$ H1N1, epidemiology $\cdot$ Oseltamivir

\begin{abstract}
Objectives: To investigate the epidemiological and clinical features of 308 hospitalized patients suffering from infection with novel H1N1 influenza virus in China from May to August 2009, and to examine the effects of oseltamivir treatment for mild cases. Methods: Information on H1N1 influenza patients confirmed by real-time RT-PCR assay was gathered and analyzed from an influenza surveillance system, including demographic features, clinical symptoms and signs, therapeutic regimen, and duration of fever and virus shedding. Results: The clinical course of infected individuals appeared mild. Mainly young adults were affected. Most cases had low or mid-level fever, cough, headache, rhinorrhoea, and sore throat. Few patients had vomiting (1.3\%) and diarrhea (3.9\%). Oseltamivir treatment did not shorten the duration of fever. Furthermore, early oseltamivir treatment as well as early conventional supportive treatment without antiviral drugs contributed to a reduction in the duration of
\end{abstract}

virus shedding. Conclusions: In the first pandemic wave, novel H1N1 virus caused disease primarily in adults, causing mild febrile illness. Mildly ill patients cleared the virus rapidly even in the absence of oseltamivir treatment.

Copyright $\odot 2010$ S. Karger AG, Basel

\section{Introduction}

During the spring of 2009, a novel swine-origin influenza A (H1N1) virus was identified in America and subsequently spread throughout the world $[1,2]$. The World Health Organization (WHO) raised the pandemic level to phase 6 on June 11, which indicated that a global pandemic had begun [3]. As of November 8, 2009, more than 206 countries and territories had reported laboratoryconfirmed cases of novel H1N1 influenza, including over 6,250 deaths [4]. The novel H1N1 virus is a triple reassortant influenza virus, which is genetically and antigenically distinct from seasonal influenza viruses $[5,6]$. As a result, seasonal influenza vaccines do not provide effective cross-protection against novel $\mathrm{H} 1 \mathrm{~N} 1$ virus [7]. Be-

\section{KARGER}

Fax +41 613061234 E-Mail karger@karger.ch www.karger.com
(C) 2010 S. Karger AG, Basel

0300-5526/11/0543-0164\$38.00/0

Accessible online at:

www.karger.com/int
Boping Zhou

Department of Infectious Diseases

Renmin Hospital of Wuhan University

99 Ziyang Rd, Wuhan 430060 (China)

Tel. +86755 2560 4033, Fax +86 7552560 4034, E-Mail szzhanggl@ gmail.com 
cause of this, novel H1N1 vaccines have been developed and used to immunize high-risk populations in China as well as many other countries.

In the view of current available data, infections with novel H1N1 virus are mild as compared with the 1918 influenza. The mortality rate caused by novel H1N1 influenza ranges from 0.20 to $1.23 \%$ [8]. Information on clinical features and risk factors for severity among patients with novel H1N1 virus infection are still emerging. In contrast to seasonal influenza, in which adults with underlying diseases appear to be at high risk of severe illness and deaths $[9,10]$, novel H1N1 influenza mostly occurred in younger individuals, including pregnant women. In the beginning of the pandemic, all novel H1N1 influenza patients were hospitalized in local infectious disease hospitals in China. On July 9, 2009, the government revised the hospitalization policy because of the rapid increase in the number of cases. From this date, patients with mild symptoms were placed under medical observation at home, and only severely ill patients were hospitalized. This report summarizes epidemiological and clinical features of 308 hospitalized novel H1N1 influenza patients in the first pandemic wave in China.

\section{Materials and Methods}

\section{Surveillance and Data Collection}

Since the Severe Acute Respiratory Syndrome (SARS) epidemic in 2003, a national network for monitoring public health emergencies has been put in place. Patients with influenza-like illness (ILI) were examined at the nearest healthcare facilities and entered into the surveillance system. ILI was defined as fever $\left(>37.5^{\circ}\right)$, cough, and at least 1 additional symptom or sign, such as sore throat, headache, rhinorrhea, arthralgias, myalgia, prostration, nasal congestion or diarrhea, and irritability in infants $[11,12]$. Pharyngeal swabs were taken and submitted to local branches of the Chinese Centers for Disease Control and Prevention (CDC) for detecting novel H1N1 virus, together with a case report containing clinical and epidemiological data, including health conditions, demographic data, tobacco use, influenza vaccinations, recent travel history, history of contact with an individual with novel H1N1 virus infection or ILI, symptoms, and vital signs.

\section{Laboratory Confirmation}

Patients with novel H1N1 virus infection were confirmed by a real-time RT-PCR assay developed by the United States CDC and recommended by WHO [13]. Viral loads of clinical samples were determined by comparison with a standard real-time RT-PCR curve generated from serial 10 -fold dilutions of positive viral RNA control provided by Dr. Y. Guan, at the University of Hong Kong, Hong Kong SAR, China.

H1N1: Epidemiological and Clinical Features of 308 Patients
Table 1. History of travel to regions affected by the novel H1N1 pandemic among our 308 hospitalized cases

\begin{tabular}{lrrlrr}
\hline Country & $\mathrm{n}$ & $\%$ & Country & $\mathrm{n}$ & $\%$ \\
\hline America & 46 & 14.9 & Malaysia & 3 & 0.9 \\
Australia & 26 & 8.4 & Japan & 3 & 0.9 \\
Indonesia & 21 & 6.8 & Korea & 3 & 0.9 \\
Canada & 17 & 5.5 & New Zealand & 2 & 0.6 \\
Thailand & 9 & 2.9 & France & 5 & 1.6 \\
England & 9 & 2.9 & China Hongkong & 21 & 6.8 \\
Philippines & 6 & 1.9 & China Mainland & 137 & 44.5 \\
\hline
\end{tabular}

From May 1 to August 5, a total of 308 PCR-positive cases were hospitalized in 3 infectious disease hospitals located in 3 different cities (Shenzhen Third Renmin Hospital, Guangzhou Eighth Renmin Hospital and Beijing Youan Hospital). The day of admission was considered to be hospital day 0. Among the 308 confirmed cases, the median age was 22.2 years (range 7 months to 79 years) and median length of hospital stay was 5.3 days. There were 165 male and 143 female patients; 7 patients had significant pre-existing underlying medical conditions, including asthma, diabetes, hyperpiesia, arthritis, and morbid obesity.

Statistical Analysis

Statistical analysis included descriptive statistics and the results were expressed as mean \pm SEM, the median or range. Student's $t$ test and the $\chi^{2}$ test were used to compare statistical significance between 2 groups of patients, while 1-way analysis of variance (ANOVA) of the general linear model was used to compare statistical significance among 3 or more groups (GraphPad Prism software, version 4.0). In these analyses, $\mathrm{p}<0.05$ was considered to be statistically significant.

\section{Results}

Of 308 cases investigated, only 5 patients had received seasonal influenza vaccination in the previous 12 months. Eighty-two patients (26.6\%) reported contact with an individual with ILI, and 93 (30.2\%) reported contact with a patient who had novel H1N1 virus infection. The travel histories to novel H1N1 pandemic regions of 308 hospitalized cases are presented in table 1 . We found that novel H1N1 influenza preferentially affected the 10- to 29 -year-old age group, which accounted for almost $69.9 \%$ of patients (fig. 1), similar to the previous report [15].

Clinically, fever was most frequently observed and the average peak temperature was $38.52 \pm 0.85^{\circ}$ (mean \pm SEM). Among them $58.1 \%$ of patients had fever between $38^{\circ}$ and $39^{\circ}$ (fig. 2). Besides fever, cough (61.2\%), headache $(24.8 \%)$, rhinorrhea $(27.1 \%)$ and sore throat $(30.2 \%)$ were the most common symptoms. In addition, $1.3 \%$ of pa-

Intervirology 2011;54:164-170 


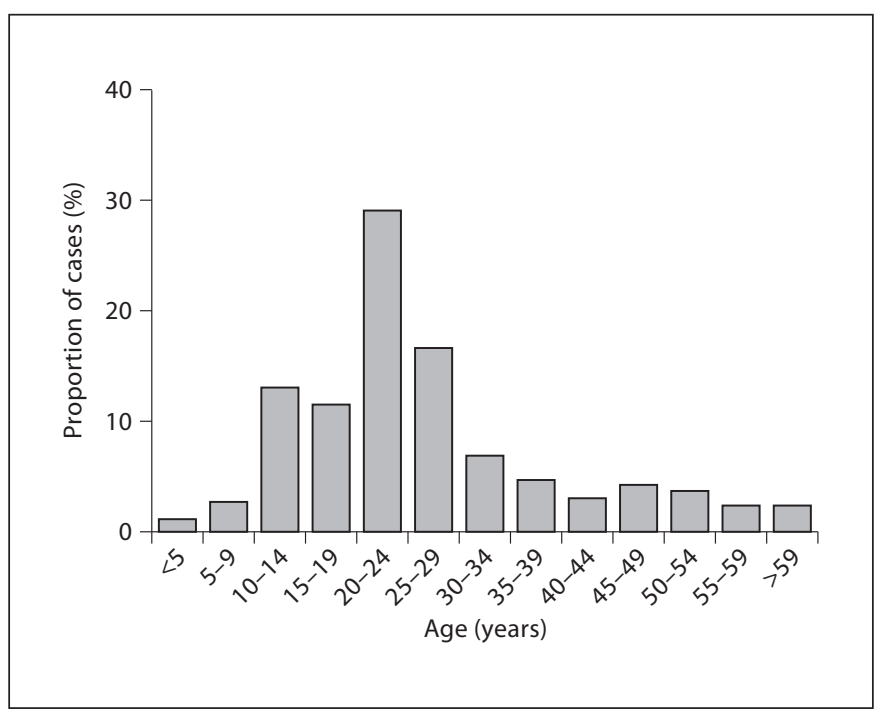

Fig. 1. Age distribution of 308 hospitalized cases with novel H1N1 virus infection in China during the first pandemic wave.

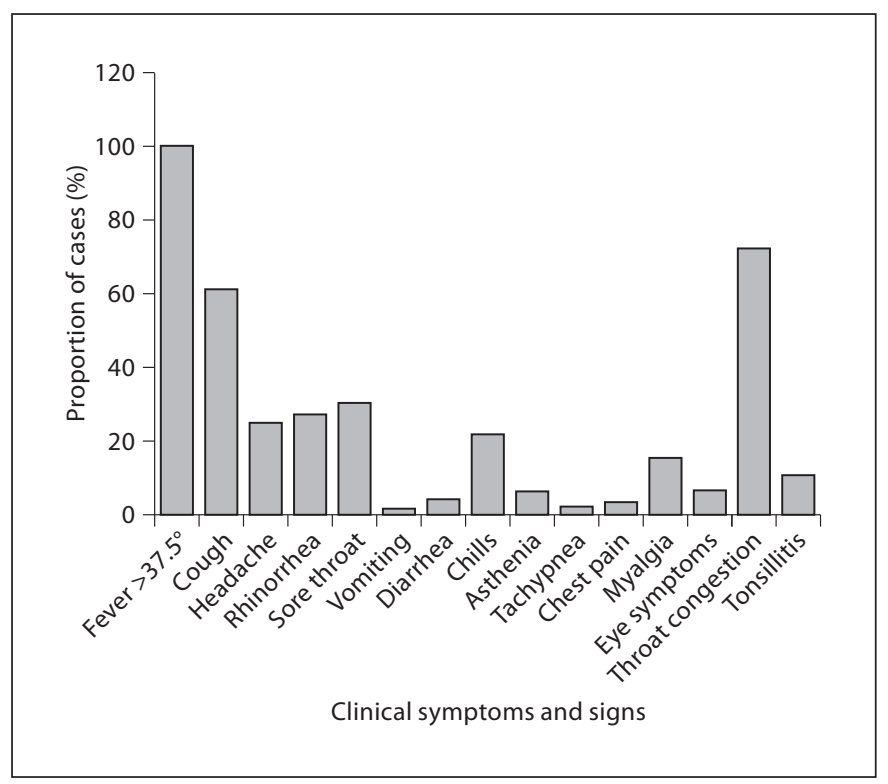

Fig. 3. Clinical symptoms and signs distribution of 308 hospitalized cases with novel H1N1 virus infection in China during the first pandemic wave.

tients had nausea and/or vomiting and 3.9\% of patients had diarrhea, which were much lower than those reported in USA [16] and in Japan [17]. Other symptoms and signs involved chills, asthenia, tachypnoea, chest pain,

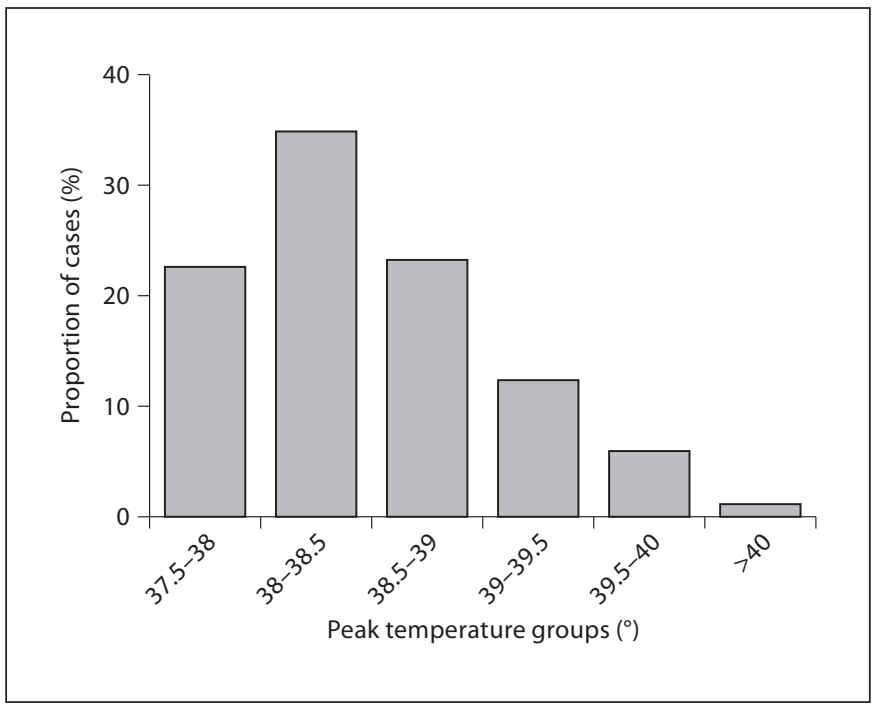

Fig. 2. Distribution of the peak temperature during disease course for 308 hospitalized cases with novel H1N1 virus infection in China during the first pandemic wave.

myalgia, eye symptoms (ophthalmalgia, dacryorrhea or onjunctivitis), throat congestion and tonsillitis (fig. 3).

As observed elsewhere [18], the majority of patients with novel H1N1 virus infection, regardless whether they had underlying medical condition, had a short clinical course and recovered quickly with median time from symptom onset to resolution of 5.8 days (range 4-7 days). Only 12 patients had concurrent pneumonia involving Streptococcus pneumoniae, Staphylococcus aureus, Gramnegative rods, or mycoplasma. A 63-year-old patient was infected by methicillin-resistant $S$. aureus (MRSA) isolated from endotracheal aspirate. Seventy-two patients (23.4\%) had leucopenia (leukocyte counts $<4,000 \mathrm{~mm}^{2}$ ) and $38(12.3 \%)$ had thrombocytopenia (platelet counts $<100,000 \mathrm{~mm}^{2}$ ) on admission.

As shown in figure 4, before July 9, 169 patients received anti-viral treatment: 150 oseltamivir, 7 zanamivir and 12 both. After July 9, when the treatment guidelines were revised, another 9 patients were also given oseltamivir treatment as a result of morbid obesity (BMI $\geq 40$ ), being under 2 years old, underlying diabetes, or complicating pneumonia. The remaining 130 patients only received conventional supportive therapy with no specific antiviral treatment.

To compare the duration of fever in patients with or without oseltamivir treatment, we found that the average time of fever in oseltamivir treatment group was $70.37 \pm$ $36.17 \mathrm{~h}$; while the average time of fever in the no anti-viral 
Fig. 4. Clinic flow diagram of 308 hospitalized cases categorizations based on different treatment pathways.

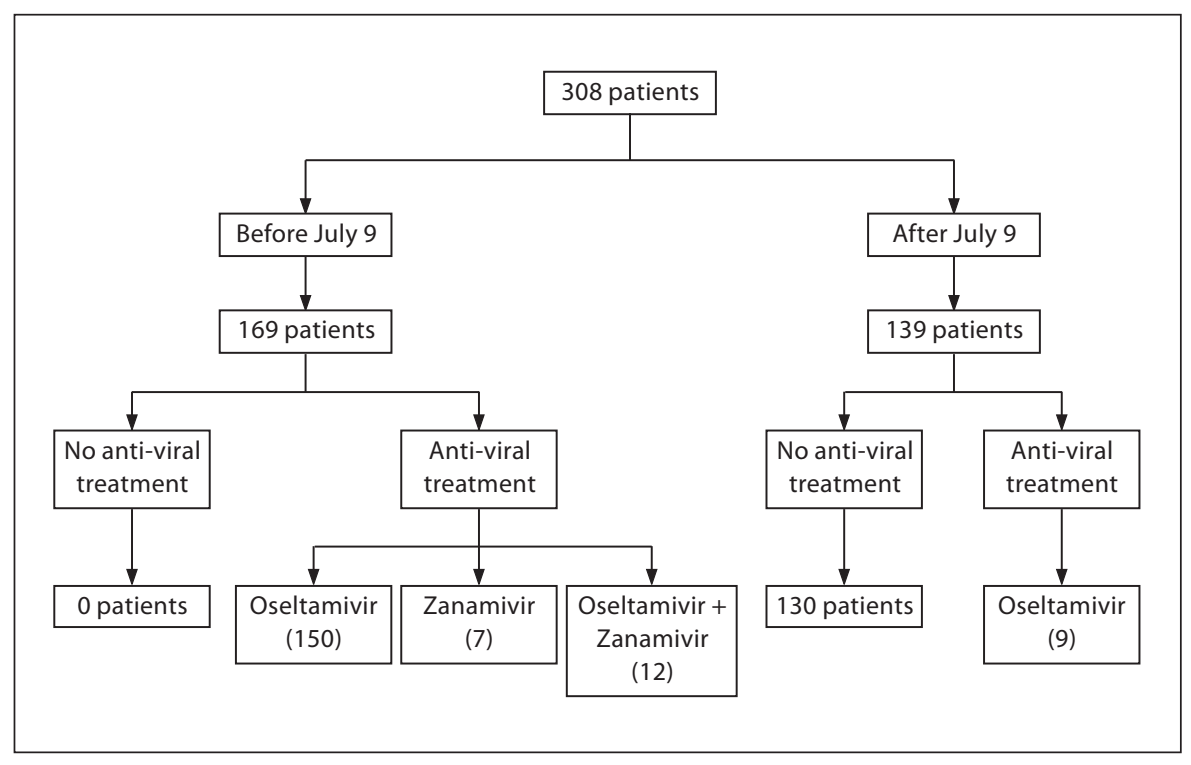

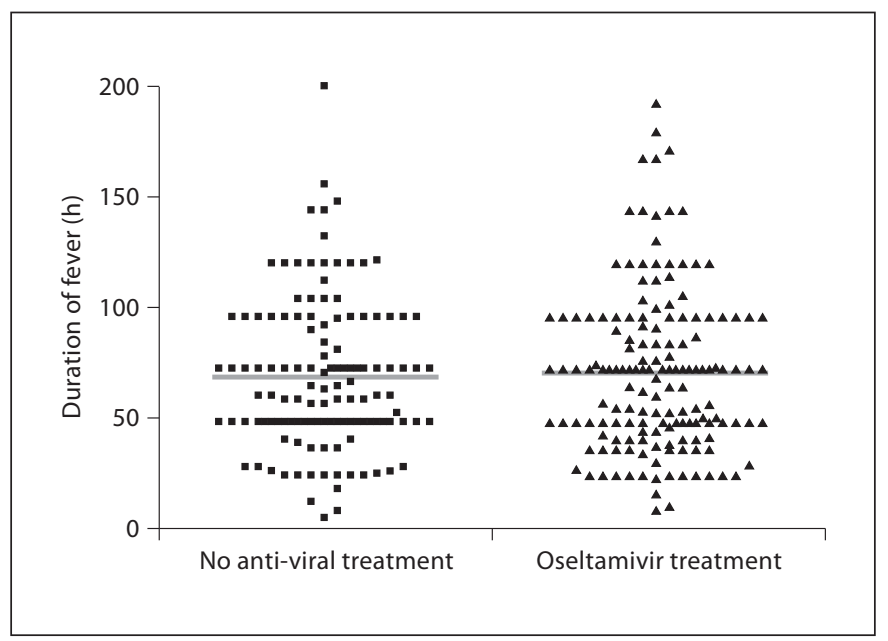

Fig. 5. The duration of fever (in hours) in 130 novel H1N1 influenza patients who received no antiviral treatment and in 159 patients who received oseltamivir treatment. The gray lines represent the median. No significant difference was observed between the 2 groups; $\mathrm{p}=0.624$.

treatment group was $68.33 \pm 34.05 \mathrm{~h}(\mathrm{p}=0.624$; fig. 5). These 2 treatment groups were then further divided into a younger group (age $<18$ years) and an adult group (age $\geq 18$ years). Still no statistical differences were observed in either age group (data not shown).

To determine the potential correlation between viral loads and antiviral treatment, pharyngeal swabs were collected for RNA extraction from some patients daily.

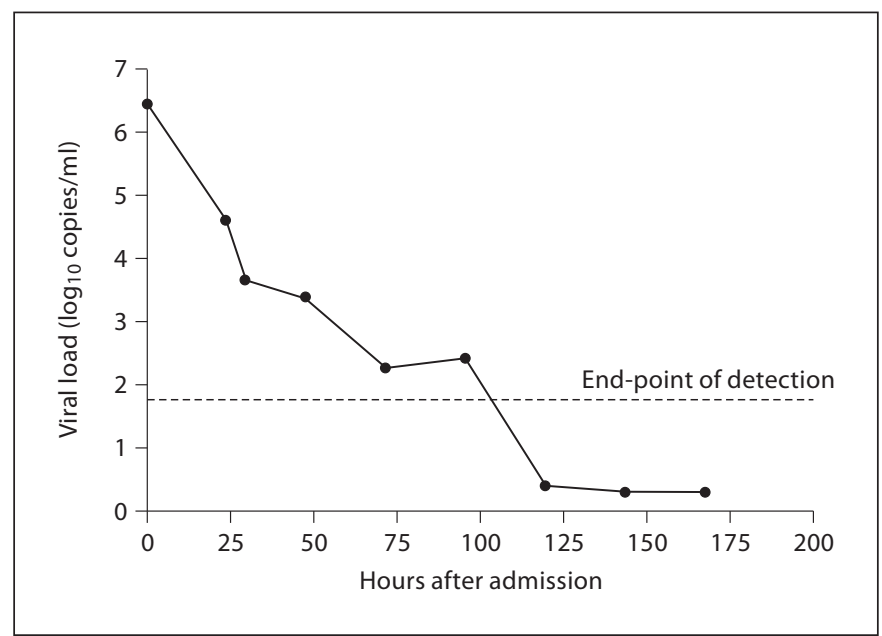

Fig. 6. Dynamic changes of viral loads determined with quantitative real-time RT-PCR assay for 1 patient from admission to discharge. The horizontal line represents the end-point of detection for quantitative real-time RT-PCR assay.

Viral loads were quantified with quantitative real-time RT-PCR assay. As shown in figure 6, RNA from 1 patient was positive until $96 \mathrm{~h}$ after admission. Then it was at undetectable level for the 3 consecutive days.

The duration of virus shedding was shorter in patients who received oseltamivir within $24 \mathrm{~h}$ after illness onset than in those who received oseltamivir more than $24 \mathrm{~h}$ after illness onset. Similar to those observed in the oselta- 


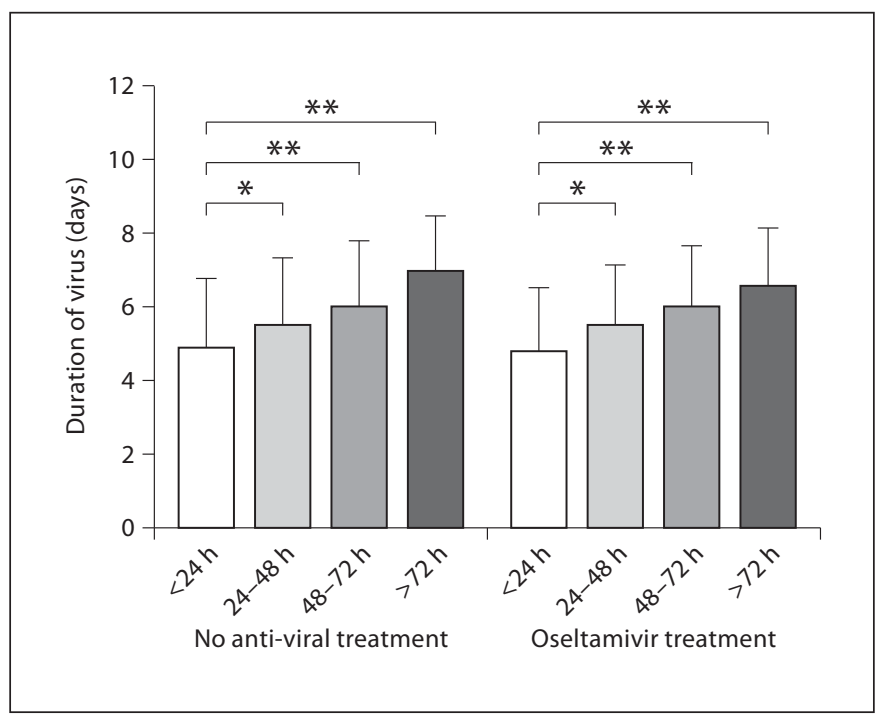

Fig. 7. The duration of virus shedding (in days) from onset of symptoms in those who received no antiviral treatment and in those who received oseltamivir treatment at different time points after onset of illness. The error bars represented + SEM of values. ${ }^{*} \mathrm{p}<0.05,{ }^{* *} \mathrm{p}<0.01$.

mivir treatment group, among patients who received no specific antiviral treatment these shorter periods were also observed in those who received conventional supportive treatment within $24 \mathrm{~h}$ after illness onset (fig. 7). Furthermore, there was no significant difference in the duration of virus shedding between the group who received oseltamivir treatment within $24 \mathrm{~h}$ and the group who only received conventional supportive treatment within $24 \mathrm{~h}$, indicating that earlier therapeutic intervention regardless of whether it involves oseltamivir or not contributes to a reduction in the duration of virus shedding.

\section{Discussion}

In March 2009, a novel H1N1 virus was recognized as having caused a large outbreak in Mexico [19], with subsequent cases in multiple other countries. After the first novel H1N1 influenza case was confirmed in China, the number of patients increased quickly. Initially the majority of cases were patients who had come from other countries with ongoing pandemic H1N1. Later, the majority of cases were through local infection rather than imported cases. This epidemiological pattern also occurred in other areas, such as Japan [17], Bolivia [20] and the city of Birmingham in the UK [18].
Similar to the 1918 H1N1 virus [21] and other previous reports on the novel $\mathrm{H} 1 \mathrm{~N} 1$ virus [22], our present study also found novel H1N1 influenza primarily affected young adults in the 18- to 24-year-old age group, which was slightly older than seasonal influenza, which occurred among 2- to 17-year-olds [15]. Similar to those observed in peak periods of seasonal influenza [23], the present study found that fever, cough, sore throat, headache, and rhinorrhea were the main symptoms of novel H1N1 influenza, which were highly predictive for the diagnosis of novel H1N1 influenza during the outbreak. Previous studies showed that a higher proportion of patients with gastrointestinal symptoms was observed as compared to seasonal influenza patients $[16,17]$. In the present study we found less than $5 \%$ of patients had gastrointestinal symptoms.

The less severe and non-fatal cases found in the present study are different from more severe and fatal cases recently reported around the world [4]. As in seasonal influenza patients, medical conditions were associated with severity and mortality of novel H1N1 virus infection. Investigations in the USA showed that more than $70 \%$ of H1N1 admissions were individuals with underlying medical conditions [16]. In the present study 7 patients with medical conditions did not exhibit severe disease. However, the number of cases in this study was too low to draw any conclusion. Previous data showed that secondary infection caused by MRSA correlated with mortality of seasonal influenza [24]. In our study, the secondary MRSA infection in the 63-year-old pneumonia patient was effectively controlled after the treatment with vancomycin.

Neuraminidase inhibitors including oseltamivir and zanamivir had been widely used to treat novel H1N1 influenza. Recent data suggested that even if initiated late, oseltamivir treatment could reduce mortality of hospitalized patients with influenza pneumonia [25], meanwhile, reports from Canada also showed that patients who received antiviral therapy within $48 \mathrm{~h}$ after illness onset were less likely to die [26]. There have been increasing reports of sporadic cases with oseltamivir-resistant novel H1N1 virus with the H275Y mutation in the neuraminidase gene $[27,28]$. In the present study, we showed that for patients with mild disease oseltamivir treatment does not shorten the duration of fever, which was different from a previous report [17]. Theoretically, as a neuraminidase inhibitor, oseltamivir could inhibit virus release and reduce virus replication, so oseltamivir treatment could shorten the duration of virus shedding. However, we show that both early oseltamivir treatment and early conventional supportive treatment have the same effect 
on the duration of viral shedding. Based on this finding, we conclude that it is not necessary to treat patients with mild disease with oseltamivir.

Our present study has several limitations. It is a retrospective clinical analysis, so division of patients into subgroups may have been subject to bias. Methods to gather clinical information were not standardized. As pharyngeal swab samples may have lower sensitivity, some falsenegative results might have occurred. Most patients in this study had mild disease, which limited the research on epidemiological and clinical features of patients with severe novel H1N1 influenza. Finally, some data are incomplete. However, all these drawbacks are inherent in retrospective clinical studies.

\section{Acknowledgments}

This study was supported by the National Natural Science Foundation of China (grant No. 30873264). We express deep appreciation to the medical and laboratory personnel who provided clinical care during this outbreak and who collected much of the information used in this report. The findings and conclusions in this report are those of the authors and do not necessarily represent the views of the Chinese Ministry of Health or CDC.

\section{References}

1 Naffakh N, van der Werf S: April 2009: an outbreak of swine-origin influenza A (H1N1) virus with evidence for human-tohuman transmission. Microbes Infect 2009; 11:725-728.

$\checkmark 2$ Dawood FS, Jain S, Finelli L, Shaw MW, Lindstorm S, Garten RJ, Gubareva LV, Xu X, Bridge CB, Uyeki TM, Novel Swine-Origin Influenza A (H1N1) Virus Investigation Team: Emergence of a novel swine-origin influenza A (H1N1) virus in humans. N Eng J Med 2009;360:2605-2615.

3 World Health Organization: Global alert and response, pandemic (H1N1) 2009, frequently asked questions: what is phase 6 ? Geneva, WHO, 2009. www.who.int/csr/ disease/swineflu/frequently_asked_questions/levels_pandemic_alert/en/index.html (accessed August 30, 2010).

4 World Health Organization: Pandemic (H1N1) 2009. Update 74. Geneva, WHO, 2009. www.who.int/csr/don/2009_11_13/en/ index.html (accessed August 30, 2010).

-5 Garten RJ, Davis CT, Russell CA, Shu B, Lindstrom S, Balish A, Sessions WM, Xu X, Skepner E, Deyde V, Okomo-Adhiambo M, Gubareva L, Barnes J, Smith CB, Emery SL, Hillman MJ, Rivailler P, Smagala J, de Graaf M, Burker DF, Fouchier RA, Pappas C, Alpuche-Aranda CM, López-Gatell H, Olivera H, López I, Myers CA, Faix D, Blair PJ, Yu C, Keene KM, Dotson PD Jr, Boxrud D, Sambol AR, Abid SH, St George K, Bannerman T, Moore AL, Stringer DJ, Blevins P, DemmlerHarrison GJ, Ginsberg M, Kriner P, Waterman S, Smole S, Guevara HF, Belongis EA, Clark PA, Beatrice ST, Donis R, Katz J, Finelli L, Bridges CB, Shaw M, Jernigan DB, Uyeki TM, Smith DJ, Klimov AI, Cox NJ: Antigenic and genetic characteristics of swine-origin 2009 A (H1N1) influenza viruses circulating. Science 2009;325:197-201.
-6 Trifonov V, Khiabanian H, Greenbaum B, Rabbadan R: The origin of the recent swine influenza A (H1N1) virus infecting humans. Euro Surveill 2009;14:19193.

-7 Chen H, Wang Y, Liu W, Zhang J, Dong B, Fan X, de Jong MD, Farrar J, Riley S, Smith GJ, Guan Y: Serologic survey of pandemic (H1N1) 2009 virus, Guangxi Province, China. Emerg Infect Dis 2009;15:1849-1850.

-8 Echevarría-Zuno S, Mejía-Aranguré JM, Mar-Obeso AJ, Grajales-Muniz C, RoblesPérez E, González-León M, Ortega-Alvarez MC, Gonzalez-Bonilla C, Rascón-Pacheco RA, Borja-Aburto VH: Infection and death from influenza A H1N1 virus in Mexico: a retrospective analysis. Lancet 2009;374: 2072-2079.

-9 Castro-Jiménez MA, Castillo-Pabón JO, Rey-Benito GJ, Pulido-Domínguez PA, Barbosa-Ramírez J, Velandia-Rodriguez DA, Angulo-Martínez ES: Epidemiologic analysis of the laboratory-confirmed cases of influenza $\mathrm{A}(\mathrm{H} 1 \mathrm{~N} 1) \mathrm{v}$ in Colombia. Euro Surveill 2009;14:19284.

10 Ciblak MA, Albayrak N, Odabas Y, Basak Altas A, Kanturvardar M, Hasoksuz M, Sucakli B, Korukluoglu G, Bal E, Ertek M, Badur S: Cases of influenza $\mathrm{A}(\mathrm{H} 1 \mathrm{N1}) \mathrm{v}$ reported in Turkey, May-July 2009. Euro Surveill 2009;14:19304.

11 Boivin G, Hardy I, Tellier G, Maziade J: Predicting influenza infections during epidemics with use of a clinical case definition. Clin Infect Dis 2000;31:1166-1169.

12 Navarro-Mari JM, Perez-Ruiz M, CantudoMunoz P, Petit-Gancedo C, Jimenez-Valera $\mathrm{M}$, Rosa-Fraile M: Influenza-like illness criteria were poorly related to laboratory-confirmed influenza in a sentinel surveillance study. J Clin Epidemiol 2005;58:275-279.
13 Centers for Disease Control and Prevention protocol of real time RT-PCR for influenza A (H1N1). Atlanta, CDC, 2009.

14 Cao B, Li XW, Shu YL, Jiang N, Chen SJ, Xu $\mathrm{XY}$, Wang C: Characteristics of 3 early cases of influenza A pandemic (H1N1) 2009 virus infection, People's Republic of China, 2009. Emerg Infect Dis 2009;15:1418-1422.

15 Crum-Cianflone NF, Blair PJ, Faix D, Arnold J, Echols S, Sherman SS, Tueller JE, Warkentien T, Sanguineti G, Bavaro M, Hale BR: Clinical and epidemiologic characteristics of an outbreak of novel H1N1 (swine origin) influenza A virus among United States military beneficiaries. Clin Infec Dis 2009; 49:1801-1810.

-16 Jain S, Kamimoto L, Bramley AM, Schmitz $\mathrm{AM}$, Benoit SR, Louie J, Sugerman DE, Druckenmiller JK, Ritger KA, Chugh R, Jasuja S, Deutscher M, Chen S, Walke JD, Duchin JS, Lett S, Soliva S, Wells EV, Swerdlow D, Uyeki TM, Fiore AE, Olsen SJ, Fry $\mathrm{AM}$, Bridges CB, Finelli L: Pandemic Influenza A (H1N1) Virus Hospitalization Investigation Team. 2009. Hospitalized patients with $2009 \mathrm{H} 1 \mathrm{~N} 1$ influenza in the United States, April-June 2009. N Eng J Med 2009; 361:1935-1944.

17 Komiya N, Gu Y, Kamiya H, Yahata Y, Matsui T, Yasui Y, Okabe N: Clinical features of cases of influenza A (H1N1) virus in Osaka prefecture, Japan, May 2009. Euro Surveill 2009;14:1-3.

18 Health Protection Agency, Health Protection Scotland, National Public Health Services for Wales, HPA Northern Ireland Swine influenza investigation teams: Epidemiology of new influenza A (H1N1) virus infection, United Kingdom, April-June 2009. Euro Surveill 2009;14:19232. 
19 Centers for Disease Control and Prevention: Outbreak of swine-origin influenza A (H1N1) virus infection - Mexico, MarchApril 2009. MMWR Morb Mortal Wkly Rep 2009;58:467-470.

-20 Gianella A, Walter A, Revollo R, Loayza1 R, Vargas1 J, Roca1 Y: Epidemiologic analysis of the influenza A (H1N1)v outbreak in Bolivia, May-August 2009. Euro Surveill 2009;14: 19323.

-21 Morens DM, Fauci AS: The 1918 influenza pandemic: insights for the 21 st century. J Infect Dis 2007; 195:1018-1028.

-22 Louie JK, Acosta M, Winter K, Jean C, Gavali $S$, Schechter R, Vugia D, Harriman $K$, Matyas B, Glaser CA, Samuel MC, Rosenberg J, Talarico J, Hatch D, California Pandemic (H1N1) Working Group: Factors associated with death or hospitalization due to pandemic 2009 influenza A (H1N1) infection in California. JAMA 2009;302:18961902.
23 Monto AS: The risk of seasonal and pandemic influenza: prospects for control. Clin Infect Dis 2009;48(suppl 1):20-25.

24 Finelli L, Fiore A, Dhara R, Brammer L, Shay DK, Kamimoto L, Fry A, Hageman J, Gorwitz R, Bresee J, Uyeki T: Influenza-associated pediatric mortality in the United States: increase of Staphylococcus aureus coinfection. Pediatrics 2008;22:805-811.

25 Centers for Disease Control and Prevention (CDC): Updated interim recommendations for the use of antiviral medications in the treatment and prevention of influenza for the 2009-2010 season. Atlanta, CDC, 2009. www.cdc.gov/h1n1flu/recommendations. htm
26 McGeer A, Green KA, Plevneshi A, Shigayeva A, Siddiqi N, Rabound J, Low DE; Toronto Invasive Bacterial Diseases Network: Antiviral therapy and outcomes of influenza requiring hospitalization in Ontario, Canada. Clin Infect Dis 2007;45:1568-1575.

27 Centers for Disease Control and Prevention: Oseltamivir resistant 2009 pandemic influenza A (H1N1) virus infection in two summer campers receiving prophylaxia-North Carolina, 2009. MMWR Morb Mortal Wkly Rep 2009;58:969-972.

28 Baz M, Abed Y, Papenburg J, Bouhy X, Hamelin ME, Boivin G: Emergence of oseltamivir-resistant pandemic $\mathrm{H} 1 \mathrm{~N} 1$ virus during prophylaxis. N Engl J Med 2009;361: 2296-2297. 